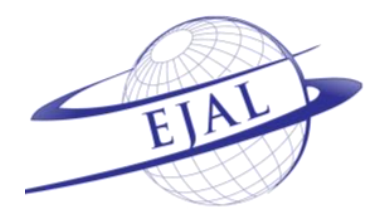

\title{
Examining Turkish University Students' Sense of Achievement, Motivation, and Anxiety: A Comparison of the English- and French-Medium Education Systems
}

\author{
Hülya Fidan Uçar a * (D), Adem Soruç b † (D) \\ a Galatasaray University, Ortaköy Campus, İstanbul, 34347, Turkey \\ ${ }^{b}$ University of Bath, Department of Education, Language and Educational Practices, BA2 7AY, United Kingdom
}

\section{APA Citation:}

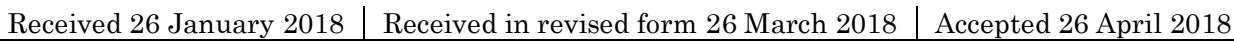

Fidan Uçar, H. \& Soruç, A. (2018). Examining Turkish university students' sense of achievement, motivation, and anxiety: A comparison of the English- and French-medium education systems. Eurasian Journal of Applied Linguistics, 4(2), 177-191. doi: 10.32601/ejal.464096

\begin{abstract}
Foreign language-medium instruction at tertiary level is receiving great attention in our decade. Thus, this study examines the significance of the following psychological factors for Turkish students enrolled in tertiary education: (i) sense of achievement, (ii) motivation, and (iii) anxiety. In particular, it focuses on the perceptions of Turkish students receiving tertiary education by an English-medium instruction (EMI) or a French-medium instruction (FMI). The study also focuses on the impact of context on students' perceptions. To collect data, students enrolled in an EMI $(\mathrm{N}=144)$ and FMI $(\mathrm{N}=214)$ were administered a five-point Likert scale survey. Seventeen students were also interviewed for this study, and they represented one Turkish public university and two private universities. The study revealed that the students in both contexts had a higher sense of achievement, motivation, and low level of anxiety whilst receiving foreign language as the medium of instruction. Regarding the contextual difference, however, although the EMI and FMI students both perceived themselves successful, the former was found to be more motivated, whereas the latter was found to be more anxious. This paper discusses the implications of these findings as well as giving suggestions for further research.
\end{abstract}

(C) 2018 EJAL \& the Authors. Published by Eurasian Journal of Applied Linguistics (EJAL). This is an open-access article distributed under the terms and conditions of the Creative Commons Attribution license (CC BY-NC-ND) (http://creativecommons.org/licenses/by-nc-nd/4.0/).

Keywords: English-medium instruction; French-medium instruction; achievement; motivation; anxiety; context

\section{Introduction}

The Bologna Declaration was adopted by 29 European countries in 1999 in order to facilitate the development of multilingual and multicultural societies (Coyle, 2008). To this end, the declaration called for the introduction of a foreign language as a medium of instruction generally at tertiary level, thus popularizing also the importance of medium of instruction when delivering the content of the subject courses (Dearden,

\footnotetext{
* Corresponding Author.

E-mail address: hfidan@gsu.edu.tr

† adamsoruc@gmail.com
} 
2015). Introducing a foreign language as the medium of instruction in an education system, however, poses several challenges, especially for the students. Therefore, it is pertinent to probe why educators and learners alike "undertake the very challenging task of teaching and learning in a language which is not their own" (Soruç \& Griffiths, 2018, p. 10). Given the growing importance of English and its global penetration, universities seeking to attract international students and staff have adopted, more often than not, English as a medium of instruction (Dearden \& Macaro, 2016). This is especially true of European universities (Doiz, Lasagabaster, \& Sierra, 2011, p. xvii). For instance, in Turkey, English is the medium of instruction in some state and private universities. Notably, French has also been adopted as the medium of instruction in one state university in Turkey. In this context, this study examines the significance of the following psychological factors for Turkish university students enrolled in an EMI and FMI: (i) sense of achievement, (ii) motivation, and (iii) anxiety. This study also compares the perceptions of these students.

\section{Previous studies}

A significant number of studies have focused on the sense of achievement of students receiving foreign language as the medium of instruction. For instance, in the Australian context, Courcy and Burston (2000) found that students enrolled in a mathematics course in an FMI could not improve their mathematical abilities on account of the language of instruction. Nyika (2015) argues that foreign language as the medium of instruction negatively affects students' academic performance as it makes it difficult for students to understand the course content. By comparing the academic performance of students from nine different departments, Turkey, Civan and Coşkun (2016) found that an EMI negatively impacted their performance. They note that the students found it difficult to understand the English language. Similarly, a study conducted by Maalim (2017) in Zanzibar showed that students who were instructed in their mother tongue outperformed the students who were instructed in English.

Studies have also attempted to identify the motivations for students to opt for foreign language as the medium of instruction. In Turkey, Macaro, and Akıncığlu's (2017) study found that students opted for an EMI because of the prestige associated with the English language. The students also believed that proficiency in English would increase their social standing and improve their career prospects. Tolon (2014) found that teachers in Rwanda favored the EMI as they considered English to be a global language. Similarly, Kuchah (2016) found that students in Cameroon opted for English language medium instruction since proficiency in English created more opportunities for employment. In addition, Huang's (2015) study also revealed that students in Southern Taiwan also opted for English language medium instruction for the same reason.

Studies have also examined whether foreign language as the medium of instruction causes anxiety in students. For instance, Courcy and Burston (2000) found that 
students instructed in French in a mathematics course were more challenged by the French language than by the mathematical tasks. Cho's (2012) study conducted in a similar setting in Korea revealed that students were more challenged by their lack of knowledge in the language of instruction. Kagwesage (2012) found that Rwandan students were anxious as their teachers' pronunciation and speed of delivery were challenging. On the other hand, some argue that students typically believe that they can overcome these difficulties (e.g., Kırkgöz, 2005; Evans \& Morrison, 2011), while another recent study conducted by Soruç \& Griffiths (2018) found that students enrolled in an EMI were unable to manage or address affect-related difficulties, such as emotional reactions, shyness, embarrassment, boredom, and distraction.

The studies reviewed in this paper show that foreign language as the medium of instruction has become highly popular and common. However, these studies do not focus enough on contextual differences, such as the differences involved in an EMI and FMI, although, according to Macaro and Akıncığlu (2017), students' perceptions about foreign language as the medium of instruction "merit further investigation" ( $p$. 13). Notably, the present study is among the first to compare students' perceptions about their motivation to learn, sense of achievement, and anxiety in the context of EMI and FMI. In sum, this study seeks to address the following three questions:

1. What are the overall perceptions of students in both EMI and FMI context regarding their learning motivation, learning achievement, and learning anxiety?

2. Does context produce a significant difference?

3. What do students think about the EMI or FMI education systems?

\section{Method}

\subsection{Setting and participants}

This study was conducted during the spring semester of the academic year 20162017. The study focused on one state university, which followed an FMI, and two private Turkish universities, which followed an EMI. A total of 358 students (184 males and 174 females) participated in this study, whose age ranged from 18 to 23. Both the universities and the participants were sampled conveniently to collect data from all levels of study (i.e. freshman, sophomore, junior and senior), representing 17 different academic departments, in total.

\subsection{Data collection instruments and procedure}

A five-point Likert scale questionnaire, which ranged from 1 (strongly disagree) to 5 (strongly agree), and semi-structured interviews were used to collect data for this study. First, the survey over 36 items was developed by the researchers for the present study based on the results of previous studies (Arkin, 2013; Belhiah \& Elhami, 2015; Dearden \& Macaro, 2016; Huang, 2015). All the items in the survey were written in English because of its global lingua franca status, and no one disagreed with the language of the survey at the time of the data collection. Second, 
the survey was first administered to one EMI instructor. Based on the feedback received from this instructor, the survey was then piloted for 6 FMI students and 50 ELT students. By doing so, the researchers were able to identify and remove four ambiguous items from the survey. Third, after collecting the initial data from 214 students enrolled in an FMI environment, a factor analysis was conducted using the Principal Component Analysis (PCA), and before running PCA, the suitability of the data for factor analysis was assessed. The correlation matrix showed that coefficients were at .3 and above level. The Kaiser-Meyer-Oklin value was .92, which was more than the acceptable value of .6 , and Bartlett's Test of Sphericity was statistically significant $(\mathrm{p}<.000)$, confirming the factorability of the correlation matrix. Finally, as a result of PCA, it was found that 32 items formed a cohesive group with eigenvalues exceeding 1, of which 9 items pertain to learning achievement, 10 items pertain to learning motivation, and 13 pertain to learning anxiety.

Following this, semi-structured interviews were held by inviting nine EMI, eight FMI students to meet with the researchers after class. The interviews were recorded on a small recording device as well as notes taken. During the interview, the students were asked questions about (i) what motivates them, (ii) to what extent they believe they can achieve, and (iii) what makes them anxious. Some participants preferred to speak in English, whereas others responded in their mother tongue, Turkish. Participation in this study was entirely voluntary, and the participants were assured of confidentiality and anonymity. They were also informed that they could choose not to respond to any of the questions.

\subsection{Data analyses}

Quantitative data analyses were conducted using the SPSS program. First, a running factor analysis was conducted to assess whether the items in the questionnaire were reliable. Cronbach's Alpha for internal reliability was used for this purpose, and the test returned an acceptable value $(r=.876)$ (Dörnyei, 2007). This value indicated that the items measured the constructs under investigation (motivation, achievement, and anxiety). Second, the Kolmogorov-Smirnov test of normality was conducted. This test showed that none of the test items were normally distributed $(p=.002)$. Thus, the median scores were used for descriptive statistics, and Mann-Whitney U non-parametric tests were conducted for inferential statistics regarding the difference between EMI and FMI education systems.

A content analysis approach was adopted while analyzing the qualitative data (Dörnyei, 2007). A total of 316 statements were generated during the preliminary analyses, and in order to have the same standard or to define themes/codes in the same language (which was English for the majority), some were translated into English. Then, the data were coded for common themes using two raters: 40 statements pertained to learning motivation, 17 pertained to learning achievement, and 47 pertained to learning-related anxiety (open coding stage). Of the remaining 212 statements, some did not fit into a construct, whereas others were repetitive 
statements. The first author and the second rater negotiated and agreed upon the common themes, and the overall interrater reliability was found to be $95 \%$ (Miles \& Huberman, 1994). Following this, the themes were grouped into main concepts (axial coding stage). Three of the themes pertained to learning achievement such as language proficiency/competence, academic content, and learning academic subjects, and they involved a variety of sub-codes. Two of the themes pertained to learning motivation such as instrumental and integrative motivation, whereas two other themes pertained to learning anxiety including sources and effects of anxiety.

\section{Results}

\subsection{Quantitative results}

\subsubsection{Learning achievement}

Items pertaining to students' overall sense of achievement received a median rating of 4 (agree). Given the median rating of four, all students seemed to have a higher sense of achievement about what capacities they had (see Table 1); that is, they were confident enough to achieve learning in a foreign language as medium of instruction environment.

Table 1. Overall median scores for learning achievement

\begin{tabular}{llcc}
\hline Items & I am good at... & Valid & Median \\
& Percent & \\
\hline & language competency/proficiency & 52.0 & 4.00 \\
& reading academic materials & 42.7 & 4.00 \\
& writing/speaking & 47.2 & 4.00 \\
& reading/listening & 48.6 & 4.00 \\
grammar/vocabulary & 45.8 & 4.00 \\
expressing myself in class & 36.1 & 4.00 \\
& understanding questions of lecturers & 46.1 & 4.00 \\
& understanding content of lectures/class materials & 48.0 & 4.00 \\
& reading classroom materials related to subject & 49.2 & 4.00 \\
\hline
\end{tabular}

(1=strongly disagree; $2=$ disagree; $3=$ no strong opinion; $4=$ agree; $5=$ strongly agree)

\subsubsection{Learning motivation}

Median scores showed that learners were also motivated enough to opt for foreignlanguage medium instruction. In this context, almost all the items received a median rating of either 4 (agree) or 5 (strongly agree). These results are shown in Table 2. 
Table 2. Overall median scores for learning motivation

\begin{tabular}{llcc}
\hline Items & I am motivated to take EMI/FMI courses to... & Valid & Median \\
& Percent & \\
\hline & increase my school performance & 47.8 & 4.00 \\
& have a better career & 53.4 & 5.00 \\
& have better job opportunities abroad & 55.3 & 5.00 \\
& improve my professional knowledge & 40.5 & 4.00 \\
& read academic sources related to my discipline & 49.4 & 4.00 \\
produce/publish good research papers & 35.5 & 4.00 \\
familiarize myself with foreign society and culture & 26.8 & 4.00 \\
& interact with foreign students/people & 50.0 & 5.00 \\
watch movies/read for fun & 47.9 & 4.00 \\
travel abroad & 54.6 & 5.00 \\
\hline
\end{tabular}

$1=$ strongly disagree; $2=$ disagree; $3=$ no strong opinion; $4=$ agree; $5=$ strongly agree)

\subsubsection{Learning anxiety}

The median scores for items related to learning anxiety showed that students were not very anxious. Their median ratings were either 2 or 3 , meaning that they either had lack of strong opinion of or disagreed with the items asking whether they were anxious or not. The details are presented in Table 3.

Table 3. Overall median scores for learning anxiety

\begin{tabular}{llcc}
\hline Items & I have anxiety when... & $\begin{array}{c}\text { Valid } \\
\text { Percent }\end{array}$ & Median \\
\hline & learning course content & 30.3 & 3.00 \\
taking notes during lecture & 30.3 & 3.00 & 2.00 \\
finding resources related to my major & 32.0 & 3.00 \\
gaining professional knowledge of my field & 24.1 & 3.00 \\
& & 28.3 & 2.00 \\
participating in-class discussions & 35.0 & 2.00 \\
understanding lecturers & 28.3 & 3.00 \\
communicating with others & 29.1 & 2.00 \\
responding to lecturers & 29.7 & 2.00 \\
understanding terms/concepts related to my major & 27.2 & 3.00 \\
gaining critical thinking skills & 23.5 & 3.00 \\
gaining academic creativity & 21.3 & 2.00 \\
fostering my learning process & 28.9 & \\
expressing myself in exams & &
\end{tabular}

( $1=$ strongly agree; $2=$ disagree; $3=$ no strong opinion; $4=$ agree $; 5=$ strongly agree $)$ 


\subsubsection{Context-based Differences}

The Mann-Whitney U test (2 independent samples) was conducted in order to identify the significant differences, if any, between contexts (EMI and FMI). According to the highest mean rank scores, although students enrolled in an EMI seemed to achieve more than those enrolled in an FMI, the differences were not statistically significant. In addition, for six items (items $=11,12,13,15,18,19$ ), students enrolled in an EMI were more motivated than those enrolled in an FMI. On the other hand, students enrolled in an FMI felt more anxious themselves than those enrolled in an EMI for five items (items $=21,22,25,26,27$ ). These differences were also statistically significant $(\mathrm{p}<.05)$. Although effect size values (calculated using Yanati's effect size calculator) were found small, this is still an interesting finding, which will be detailed further in the Discussion section. The results are presented in Table 4.

Table 4. Mean ranks and effect sizes according to context-based differences

\begin{tabular}{|c|c|c|c|c|c|}
\hline \multicolumn{2}{|l|}{ Items } & \multirow{2}{*}{$\begin{array}{l}\text { MEAN RANK } \\
\text { EMI } \\
195.58\end{array}$} & \multirow{2}{*}{$\begin{array}{l}\text { MEAN RANK } \\
\text { FMI } \\
168.68\end{array}$} & \multirow{2}{*}{$\begin{array}{c}\text { DIFFERENCE } \\
.008\end{array}$} & \multirow{2}{*}{$\begin{array}{l}\begin{array}{l}\text { EFFECT } \\
\text { SIZE } \\
0.99 \%\end{array} \\
\end{array}$} \\
\hline 11 & $\begin{array}{l}\text { I want to learn/improve English/French for } \\
\text { my career. }\end{array}$ & & & & \\
\hline 12 & $\begin{array}{l}\text { I want to learn English/French for job } \\
\text { opportunities abroad. }\end{array}$ & 196.07 & 168.35 & .006 & $0.99 \%$ \\
\hline 13 & $\begin{array}{l}\text { I want to improve my professional } \\
\text { knowledge. }\end{array}$ & 200.33 & 165.48 & .001 & $0.99 \%$ \\
\hline 15 & $\begin{array}{l}\text { I want to produce/publish good research } \\
\text { papers. }\end{array}$ & 204.71 & 162.54 & .000 & $0.99 \%$ \\
\hline 18 & $\begin{array}{l}\text { I want to watch movies and read for fun in } \\
\text { English/French. }\end{array}$ & 199.64 & 165.04 & .001 & $0.99 \%$ \\
\hline 19 & $\begin{array}{l}\text { I want to improve my English/French to } \\
\text { travel abroad. }\end{array}$ & 196.63 & 167.08 & .003 & $0.99 \%$ \\
\hline 21 & $\begin{array}{l}\text { I have difficulty to take notes during the } \\
\text { lectures in English/French. }\end{array}$ & 157.17 & 193.76 & .001 & $0.99 \%$ \\
\hline 22 & $\begin{array}{l}\text { I have difficulty to find resources in } \\
\text { English/French. }\end{array}$ & 147.42 & 199.61 & .000 & $0.99 \%$ \\
\hline 25 & $\begin{array}{l}\text { I feel anxious to understand the teachers } \\
\text { during the lectures. }\end{array}$ & 160.87 & 191.26 & .005 & $0.99 \%$ \\
\hline 26 & I feel anxious to communicate with others. & 156.65 & 194.11 & .001 & $0.99 \%$ \\
\hline 27 & $\begin{array}{l}\text { I feel anxious to speak to the teacher in } \\
\text { English/French. }\end{array}$ & 165.33 & 188.24 & .034 & $0.99 \%$ \\
\hline
\end{tabular}

\subsection{Qualitative results}

The qualitative data revealed the following about students' perceptions about learning achievement, motivation, and anxiety. Main themes; codes; and sub-codes, along with their frequency, percentages, and number of students are shown below (Student 1-9 = EMI students; Student 10-17 = FMI). It should be remembered that the participants who responded in English were all non-native speakers of the language. Their comments, therefore, contained occasional infelicities. In order to 
preserve authenticity, their comments below are presented verbatim, although they are occasionally abbreviated.

\subsubsection{Learning achievement}

Students enrolled in the EMI as well as the FMI argued that they were able to improve their language proficiency/competence, learn effectively, and learn about different academic subjects (17 times in total). These details are presented in Table 5.

Table 5. Qualitative data about learning achievement

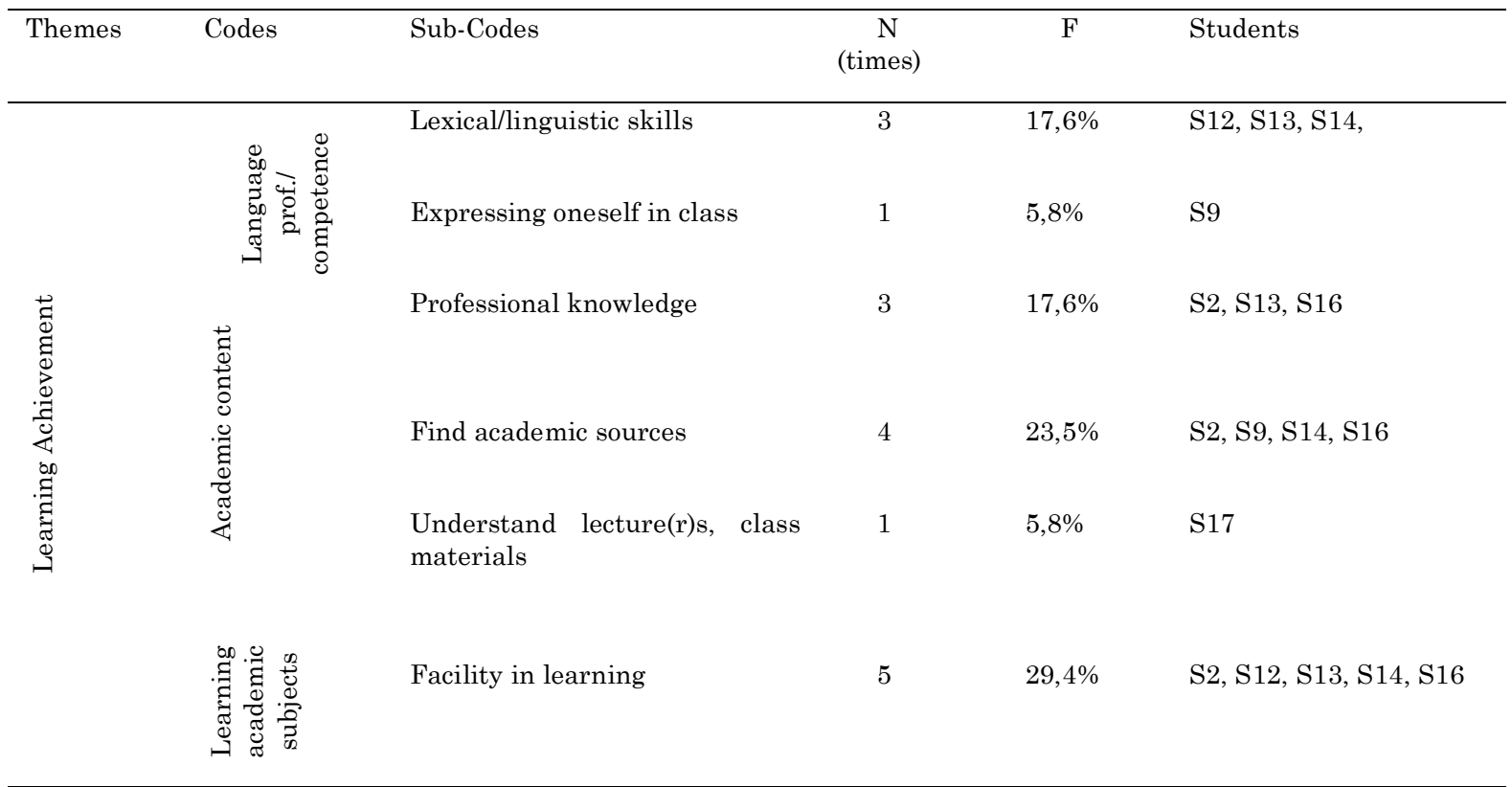

S9: English concepts of which we know the meanings facilitate to express ourselves more comfortably.

Some students $(\mathrm{n}=4 ; \mathrm{f}=23,5 \%)$ stated that they were able to access information through academic sources easier and faster given their enrollment in the EMI. In fact, some of the students enrolled in the FMI preferred English to French. For instance, one of the students stated the following:

S9: ...by knowing English we can easily find material for every single subject and find YouTube videos as well...

Another student complained about the inadequate number of resources in French:

S16: You cannot find sources in French. It is also irritating that French people rejects use of English materials.

\subsubsection{Learning motivation}

The interviews revealed that the students, irrespective of the context, were motivated to opt for foreign language as the medium of instruction. Their reasons were mostly instrumental (32 times). The students opted for foreign language as the medium of instruction in order to improve their career prospects and to gain access to more educational opportunities (40 times in total). 
Table 6. Qualitative data about learning motivation

\begin{tabular}{|c|c|c|c|c|c|}
\hline Themes & Codes & Sub-Codes & $\mathrm{N}$ (times) & $\mathrm{F}$ & Students \\
\hline \multirow{5}{*}{ 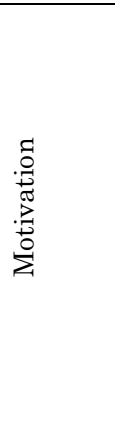 } & \multirow{3}{*}{ 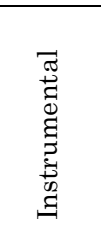 } & Career, job, study opportunities & 6 & $15 \%$ & $\mathrm{~S} 5, \mathrm{~S} 7, \mathrm{~S} 10, \mathrm{~S} 12, \mathrm{~S} 14, \mathrm{~S} 15$ \\
\hline & & Professional life & 13 & $32,5 \%$ & $\begin{array}{l}\mathrm{S} 1, \mathrm{~S} 3, \mathrm{~S} 4, \mathrm{~S} 6, \mathrm{~S} 8, \mathrm{~S} 9, \mathrm{~S} 10, \mathrm{~S} 11, \mathrm{~S} 12 \text {, } \\
\mathrm{S} 13, \mathrm{~S} 14, \mathrm{~S} 15, \mathrm{~S} 16\end{array}$ \\
\hline & & Academic sources & 13 & $32,5 \%$ & $\begin{array}{l}\mathrm{S} 2, \mathrm{~S} 3, \mathrm{~S} 4, \mathrm{~S} 5, \mathrm{~S} 6, \mathrm{~S} 7, \mathrm{~S} 8, \mathrm{~S} 9, \mathrm{~S} 10, \mathrm{~S} 11 \text {, } \\
\mathrm{S} 13, \mathrm{~S} 16, \mathrm{~S} 17\end{array}$ \\
\hline & \multirow{2}{*}{ 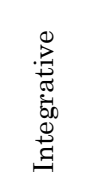 } & $\begin{array}{l}\text { Read books related to the target } \\
\text { culture }\end{array}$ & 4 & $10 \%$ & $\mathrm{~S} 5, \mathrm{~S} 7, \mathrm{~S} 8, \mathrm{~S} 10$ \\
\hline & & Communicate with people & 4 & $10 \%$ & S5, S7, S9, S10 \\
\hline
\end{tabular}

Some students stated that they were able to find sources in the foreign language in which they were instructed, but not in their native language.

S5-S6-S8: ... sources are abundant in English...You cannot achieve this in Turkish.

S11: ...All sources are in English or in French....

The EMI was valued higher compared to the FMI. Several other students argued that they were able to improve their knowledge and follow scientific developments more easily given their proficiency in a foreign language.

S6: ...Also important (English) in terms of catching up with the developments in medicine...

Students also believed that they could find better jobs given their proficiency in a foreign language.

S5: ...learning English helps us increase our job opportunities...

In addition, students also had cultural reasons to opt for foreign language as the medium of instruction, especially English (8 times in total). The following statements are relevant examples in this context:

S5: I want to learn about different cultures

S10: My main interest is to read books about French community

S9: ...Because it (English) is the world language, you can communicate with most of the people in the world...

\subsubsection{Learning anxiety}

Five factors (teacher-oriented, education policy-oriented, content-oriented, language-oriented, and learner-oriented factors) typically caused anxiety among the participants. In addition, three main effects were also found (surface learning, excess time consumption, and depleted confidence) (47 times). 
Table 7. Qualitative data about learning anxiety

\begin{tabular}{|c|c|c|c|c|c|}
\hline Themes & Codes & Sub-Codes & $\mathrm{N}$ (times) & $\mathrm{f}$ & Students \\
\hline \multirow{8}{*}{ 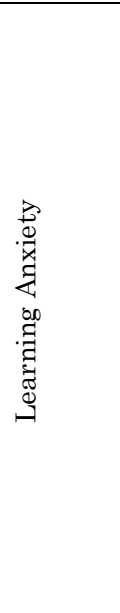 } & \multirow{5}{*}{ 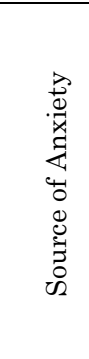 } & Teacher-oriented & 8 & $17 \%$ & $\begin{array}{l}\text { S1, S3, S4, S7, S10, S14, } \\
\text { S15, S16 }\end{array}$ \\
\hline & & Learner-oriented & 2 & $4,2 \%$ & $\mathrm{~S} 2, \mathrm{~S} 3$ \\
\hline & & Language-oriented & 5 & $10,6 \%$ & $\mathrm{~S} 13, \mathrm{~S} 14, \mathrm{~S} 15, \mathrm{~S} 16, \mathrm{~S} 17$ \\
\hline & & Content-oriented & 2 & $4,2 \%$ & $\mathrm{~S} 14, \mathrm{~S} 16$ \\
\hline & & Educational policy-oriented & 7 & $14,8 \%$ & $\begin{array}{l}\text { S3, S9, S10, S11, S12, } \\
\text { S14, S16 }\end{array}$ \\
\hline & \multirow{3}{*}{ 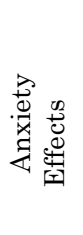 } & Surface learning & 14 & $29,7 \%$ & $\begin{array}{l}\text { S1, S2, S3, S5, S8, S9, } \\
\text { S10, S11, S12, S13, S14, } \\
\text { S15, S16, S17 }\end{array}$ \\
\hline & & Time-consuming & 4 & $8,5 \%$ & $\mathrm{~S} 2, \mathrm{~S} 7, \mathrm{~S} 13, \mathrm{~S} 16$ \\
\hline & & Feel unconfident to express oneself & 5 & $10,6 \%$ & $\mathrm{~S} 2, \mathrm{~S} 5, \mathrm{~S} 12, \mathrm{~S} 15, \mathrm{~S} 16$ \\
\hline
\end{tabular}

Participants stated the following about the factors that caused anxiety:

S1: ... they (teachers) lack English language proficiency. They cannot transmit their knowledge to us well enough... (Teacher-oriented)

S3: In fact, teachers try to explain things with very simple and basic words. They often repeat themselves ...Teachers must improve their English... They need to speak fluently. (Teacher-oriented)

S2: Some of people in class are feeling shy. Even if they know English well, they prefer not to talk in class. (Learner-oriented)

S10: French is a very difficult language... (Language-oriented)

S16: ... in some courses... it (course content) is so complicated that I even don't know what I did not understand.... (Content-oriented)

S14: Our prep school education is insufficient in terms of its length and passing grades is too low. (Education policy-oriented)

S12: French education period in school must be increased to 2 years... (Education policy-oriented)

Foreign language as the medium of instruction also had negative impacts on students, and some of the participants stated the following:

S10: French also causes memorization. When we read a theory in French, we don't often understand it... (surface learning)

S13: ... reading books is time-consuming in French. It really takes time to understand... (Time-consuming)

S3: ... (it is) stressful... we cannot express ourselves well enough in class. (Expressing oneself) 


\section{Discussion}

This study mainly sought to investigate the significance of the following psychological factors for Turkish university students $(\mathrm{N}=358)$ enrolled in an EMI and an FMI: sense of achievement, motivation, and anxiety. The median rating for students' learning achievement was 4 (agree) for all 9 items. This indicates that students enrolled in the EMI, as well as the FMI, considered themselves successful. Similar findings were reported in other studies concerning the EMI in Hong Kong (Evans \& Morrison, 2011), Southern Taiwan (Hsieh \& Kang, 2007), and Taiwan (Wu, 2006). These studies revealed that students believed enrollment in an EMI would enable them to improve their language competence, subject knowledge, and learning efficiency.

The median rating for 10 items related to motivation was either 4 (agree) or 5 (strongly agree). This means that students from both settings may have consciously opted for foreign language as the medium of instruction (in this context, English, and French). Students from both settings (EMI and FMI) opted for foreign language as the medium of instruction for two specific purposes: (i) to learn more about the language and (ii) to gain access to better standards of living in the future, including better employment. By analyzing items 16 and 17, it can be seen that the students did not opt for foreign language as the medium of instruction solely to familiarize themselves with another society or culture (item 16 ; median $=4$ ); rather, they were motivated by the desire to interact with foreign students or people (item 17 ; median $=5$ ). This finding is also supported by the participants' answers during the interviews; for instance, some students had instrumental reasons to opt for foreign language as the medium of instruction (e.g., better career or job opportunities, reaching to academic sources, etc.), and this reason outweighed the cultural motivations to opt for foreign language as the medium of instruction (e.g., cultural integration or communication with native speakers of the language). Previous studies (e.g., Huang, 2015; Kırkgöz, 2005) have also revealed similar findings.

What follows is a discussion of the significance of the median ratings of the 13 items related to anxiety. Interestingly, students either disagreed with the statements (of the items) or seemed to lack of strong opinions in this context. The data collected through the questionnaire revealed that the students were not anxious. However, in the interviews, the students spoke about a number of factors that caused anxiety (factors listed as teacher-oriented, learner-oriented, language-oriented, contentoriented, education policy-oriented) as well as the effects of anxiety (such as surface learning, excess time consumption and depleted confidence). Similarly, studies (e.g., Byun et al., 2010; Costa \& Coleman, 2013; Evans \& Morrison, 2011; Kagwesage, 2012; Kirkgöz, 2013) have found that teacher-oriented factors such as, their speed of speaking, lack of proficiency in the medium of instruction, uncommon pronunciation, and lack of concern for students' learning capabilities, place learners at a great disadvantage. Learner-oriented factors such as lack of language competence (Başbek et al., 2014; Byun et al., 2010) and shyness (Khan, 2013) also negatively affected 
students' capacity to participate in-class discussions. In addition, content-oriented factors such as lack of familiarity with course material and the demanding nature of the academic content (Costa \& Coleman, 2013) also negatively affected the students' capacity to learn. Language-oriented factors such as linguistic similarities as well as differences between students' mother tongue and their L2 and complex technical vocabulary in the target language (Arkın, 2013) caused significant disadvantages for the students. Finally, education policy-oriented reasons such as, poorly planned English and/or French prep-year programs, which do not focus on subject-specific knowledge, and the faculty's lack of concern toward the learners' language needs also caused significant disadvantages for the students. In particular, students enrolled in the FMI $(\mathrm{N}=7)$ demanded that the duration of prep-year programs be extended to two years, as opposed to the current year-long programs. These factors, in turn, have the following three effects on students: surface learning and excess time consumption as well as depleted confidence. Similar findings are reported in other studies (e.g., Arkın, 2013; Kagwesage, 2012; Kırkgöz, 2013; Soruç, Dinler, \& Griffiths, 2018). These studies show that learners without sufficient linguistic and lexical capabilities found it difficult to comprehend the subject matter in an effective manner. This, in turn, paved the way for rote learning or memorization. Some students $(\mathrm{N}=4)$ also reported that studying in a foreign language was more time-consuming (Byun et al., 2010) than studying in their mother tongue. These students used some strategies such as typically translating $(\mathrm{N}=4)$ the academic content into their mother tongue; they also discussed these subjects with their peers in their native language $(\mathrm{N}=4)$. This process is typically time-consuming $(\mathrm{N}=4)$. Students also felt insecure about expressing their thoughts in class $(\mathrm{N}=5)$. It may be argued that the lack of language proficiency decreases learner-centeredness (Cantoni, 2007), which in turn paves the way for teacher-centered instruction.

Next, this study also sought to gauge the significance of an important variable: context (EMI vs. FMI). Although students in both contexts had an equal level of sense of achievement, regarding their motivation, students enrolled in the EMI were more motivated than those enrolled in the FMI. This may be due to the fact that English is a more global language compared to French. The former is also more commonly used in the sciences. Similar findings have also been revealed by other studies (e.g., Arkin, 2013; Belhiah \& Elhami, 2015; Evans \& Morrison, 2011; Tabaro, 2015; Turhan \& Kırkgöz, 2018). In addition, as Macaro and Akıncıoğlu (2017) argue, English has a profound impact on learner's studies and their career opportunities, which in turn motivates them to opt for tertiary education in an EMI. This inference is also supported by the qualitative data of the present study. For instance, a significant number of students $(n=29)$ agreed that they would be able to gain more access to educational and professional opportunities by enrolling especially in an EMI program. Given the emergence of factors such as "internationalization and student mobility" (Macaro \& Akıncığlu, 2017, p.11), students might have more reasons to opt for foreign language as the medium of instruction; they may also be motivated by the desire to interact with foreign students and cultures. On the other hand, FMI 
students were found to be more anxious than their counterparts. According to the qualitative data $(n=5)$, they felt more anxious because they lacked language proficiency. Kırkgöz (2009) found that the language employed in prep-year programs and full-fledged academic programs were very different. Similarly, Macaro, Akıncıoğlu, and Dearden (2016) reported that prep-year programs typically do not follow theme-based language teaching. Therefore, it is important for teachers to consider learners' language needs, whereas prep-year program teachers should improve their subject knowledge.

\section{Conclusion}

This study examines the significance of the following psychological factors for Turkish students enrolled in an EMI and FMI tertiary education systems: (i) sense of achievement, (ii) motivation, and (iii) anxiety. It was mainly found that students enrolled in the EMI, as well as the FMI, had a higher sense of achievement. However, the former was more motivated to opt for foreign-language medium instruction, whereas the latter was found to be more anxious. Overall, however, students believed that they would benefit more by opting for foreign-language medium instruction. In addition, students also discussed the challenges they encountered in the EMI and FMI. It was also found that EMI and FMI educators do not pay enough attention to students' difficulties and capabilities. This aspect deserves to be studied more closely. In addition, students found collaborations between prep-year teachers and subject teachers to be "highly beneficial" for their learning process (Macaro, Akıncığlu, \& Dearden, 2016, p. 51). Moreover, collaborations between subject teachers and language teachers may yield different, yet promising, insights. Kırkgöz (2009) argues that such collaborative efforts may facilitate the organization or revision of university teacher education programs. However, the results of this study should be carefully considered as it involved only one Turkish public university and two private universities and focused merely on the perceptions of students receiving tertiary education in EMI and FMI. Future studies can also focus on a cross-sectional analysis of both students' and educators' perceptions; in particular, studies can compare the perceptions of the students and educators involved in the EMI with the perceptions of their counterparts in the FMI or any other medium. Finally, this study investigated only any effect of contextual difference on students' sense of achievement, motivation, and anxiety level when receiving course content in a foreign language as a medium of instruction. Further studies are needed to understand the role of individual differences such as gender or grade (year 1 to year 4 ) on the psychological factors in either EMI or FMI or any other medium.

\section{References}

Arkın, İ. E. (2013). English-medium instruction in tertiary level education: A case study in a Turkish university context (Doctoral dissertation). Eastern Mediterranean University. North Cyprus. Retrieved from http://i-rep.emu.edu.tr:8080/xmlui/handle/11129/634 
Başıbek, N., Dolmacı, M., Cengiz, B. C., Bür, B., Dilek, Y., \& Kara, B. (2014). Lecturers' perceptions of English medium instruction at engineering departments of tertiary level education: A study on partial English medium instruction at some state universities in Turkey. Procedia - Social and Behavioral Sciences, 116, 1819-1825. doi:10.1016/j.sbspro.2014.01.477.

Belhiah, H., \& Elhami, M. (2015). English as a medium of instruction in the Gulf: When students and teachers speak. Language Policy, 14(1), 3-23.

Byun, K., Chu, H., Kim, M., Park, I., Kim, S., \& Jung, J. (2010). English-medium teaching in Korean tertiary level education: policy debates and reality. Tertiary Level Education, 62(4), 431-449. doi:10.1007/s10734-010-9397-4

Cantoni, M. (2007). What role does the language of instruction play for a successful education? A case study of the impact of language choice in a Namibian school. Bulletin of Education and Research, 37(1), 1-10.

Cho, D. (2012). A level- and proficiency-based English language program of a science university in Korea. English Teaching, 67(4), 25-55. doi:10.15858/engtea.67.4.201212.25

Civan, A., \& Coşkun, A. (2016). The Effect of the medium of instruction language on the academic success of university students. Educational Sciences: Theory \& Practice, 16(6), 1981-2004. doi:10.12738/estp.2016.6.0052

Costa, F., \& Coleman, J. A. (2013). A survey of English-medium instruction in Italian higher education. International Journal of Bilingual Education and Bilingualism, 16(1), 3-19. doi:10.1080/13670050.2012.676621

Courcy, M. D., \& Burston, M. (2000). Learning mathematics through French in Australia. Language and Education, 14(2), 75-95. doi:10.1080/09500780008666780

Coyle, D. (2008). CLIL-a pedagogical approach from the European perspective. In N. V. Deusen-Sholl \& N. H. Hornberger (Eds.), Encyclopedia of language and education. Second and foreign language education, 4, 97-112. New York: Springer Science + Business Media LLC. http://dx.doi.org/10.1007/978-0-387-30424-3

Dearden, J. (2015). English as a medium of instruction-a growing global phenomenon. British Council. Retrieved from http://www. britishcouncil.org/education/ihe/knowledgecentre/english-language-higher-education/report-english-medium-instruction

Dearden, J., \& Macaro, E. (2016). Tertiary level education teachers' attitudes towards English medium instruction: A three-country comparison. Studies in Second Language Learning and Teaching 6(3), 455-86.

Doiz, A., Lasagabaster, D., \& Sierra, J. M. (2011). Internationalisation, multilingualism and English-medium instruction. World Englishes, 30(3), 345-359.

Dörnyei, Z. (2007). Research methods in applied linguistics: Quantitative, qualitative, and mixed Methodologies. Oxford University Press.

Evans, S., \& Morrison, B. (2011). Meeting the challenges of English-medium higher education: The first-year experience in Hong Kong. English for Specific Purposes, 30(3), 198-208. doi:10.1016/j.esp.2011.01.001

Hsieh, S.-H., \& Kang, S.-C. (2007). Effectiveness of English-medium instruction of an engineering course and strategies used by the teacher. Retrieved from http://ctld.ntu.edu.tw/rp/95_01.pdf

Huang, D. (2015). Exploring and assessing effectiveness of English medium instruction courses: The students' perspectives. Procedia - Social and Behavioral Sciences, 173, 71-78.

Kagwesage, A. M. (2012). Tertiary level education students' reflections on learning in times of academic language shift. International Journal for the Scholarship of Teaching and Learning, 6(2). doi:10.20429/ijsotl.2012.060218 
Khan, H. I. (2013). An investigation of two universities postgraduate students and their teachers' perceptions of policy and practice of English medium of instruction (EMI) in Pakistani universities (Unpublished doctoral dissertation). University of Auckland, New Zealand.

Kırkgöz, Y. (2005). Motivation and student perception of studying in an English-medium university. Journal of Language and Linguistic Studies, 1(1), 101-122.

Kırkgöz, Y. (2009). Students' and lecturers' perceptions of the effectiveness of foreign language instruction in an English-medium university in Turkey. Teaching in Tertiary Level Education, 14(1), 81-93. doi:10.1080/13562510802602640

Kırkgöz, Y. (2013). Students' approaches to learning in an English-medium higher education. The Journal of Language Teaching and Learning, 2, 30-39.

Kuchah, K. (2016). English-medium instruction in an English-French bilingual setting: issues of quality and equity in Cameroon. Comparative Education, 52(3), 311-327. doi: 10.1080/03050068.2016.1185257

Maalim, H. A. (2017). Students' underachievement in English-medium subjects: The case of secondary school in Zanzibar. Southern African Linguistics and Applied Language Studies, 35(1), 53-62. doi:10.2989/16073614.2017.1284008

Macaro, E., Akıncıoğlu, M., \& Dearden, J. (2016). English medium instruction in universities: A Collaborative Experiment in Turkey. Studies in English Language Teaching, 4(1), 51. doi:10.22158/selt.v4n1 p51

Macaro, E., \& Akıncıoğlu, M. (2017). Turkish university students' perceptions about English medium instruction: Exploring year, group, gender, and university type as variables. Journal of Multilingual and Multicultural Development, 39(3), 1-15. doi:10.1080/01434632.2017.1367398

Miles, M. B., \& Huberman, A. M. (1994). Qualitative data analysis: an expanded sourcebook. Thousand Oaks: Sage Publications.

Nyika, A. (2015). Mother tongue as the medium of instruction at developing country universities in a global context. South African Journal of Science, 111(1/2), 1-5. doi:10.17159/sajs.2015/20140005

Soruç, A., Dinler, A., Griffiths, C. (2018) Listening comprehension strategies of EMI students in Turkey. In Kırkgöz Y., Dikilitaş K. (Eds.), Key issues in English for specific purposes in higher education. English Language Education, 11. Springer, Cham.

Soruç, A., \& Griffiths, C. (2018). English as a medium of instruction: Students' strategies. ELT Journal, 72(1), 38-48.

Tabaro, D. (2015). Rwandans' motivation to learn and use English as a medium of instruction. International Journal of Humanities and Social Science, 5(2), 78-85.

Tolon, K. (2014). Teacher experiences during the shift in medium of instruction in Rwanda: Voices from Kigali public schools. British Council, 1-71.

Turhan, B., \& Kırkgöz, Y. (2018). Motivation of engineering students and lecturers toward English medium instruction in Turkey. Journal of Language and Linguistic Studies, 14(1), 261-277.

Wu, W. S. (2006). Students' attitudes toward EMI: Using Chung Hua University as an example. Journal of Education and Foreign Language and Literature, 4, 67-84.

\section{Copyrights}

Copyright for this article is retained by the author(s), with first publication rights granted to the Journal.

This is an open-access article distributed under the terms and conditions of the Creative Commons Attribution license (CC BY-NC-ND) (http://creativecommons.org/licenses/by-nc-nd/4.0/). 